\title{
Different Molecular Mechanisms Account for Drought Tolerance in Coffea canephora var. Conilon
}

\author{
Natalia G. Vieira • Fernanda A. Carneiro • Patricia S. Sujii • Jean C. Alekcevetch • \\ Luciana P. Freire • Felipe Vinecky • Sonia Elbelt • Vânia A. Silva • \\ Fábio M. DaMatta • Maria A. G. Ferrão • Pierre Marraccini • Alan C. Andrade
}

Received: 25 April 2013 / Accepted: 24 June 2013 /Published online: 9 July 2013

(C) Springer Science+Business Media New York 2013

\begin{abstract}
The effects of water deficit on photochemical parameters and expression of several candidate genes were investigated in drought-tolerant clone 73 of Coffea canephora submitted to slowly imposed water limitation. Under irrigation, this clone showed low values of stomatal conductance $\left(g_{s}\right)$ and of $\mathrm{CO}_{2}$ assimilation rates $(A)$ suggesting that it had a great efficiency in controlling stomatal closure and transpiration. After water withdrawal, this clone reached a $-3.0 \mathrm{MPa}$ after 15 days without irrigation and showed a slow decrease in the pre-dawn leaf water potential. Under drought, the suppression of $A$ was accompanied by maintenance of photochemical quenching $\left(q_{\mathrm{P}}\right)$ and internal to ambient $\mathrm{CO}_{2}$ concentration $(\mathrm{Ci} / \mathrm{Ca})$ ratios as well as by a decrease of non-photochemical quenching $\left(q_{\mathrm{N}}\right)$. This is confirmed by the transport rate $/ \mathrm{CO}_{2}$
\end{abstract}

Communicated by: Paulo Arruda

N. G. Vieira · F. A. Carneiro • P. S. Sujii - J. C. Alekcevetch •

L. P. Freire $\cdot$ F. Vinecky $\cdot$ S. Elbelt $\cdot$ P. Marraccini $\cdot$

A. C. Andrade $(\square)$

EMBRAPA Recursos Genéticos e Biotecnologia (LGM),

Parque EB, CP 02372, 70770-917 Brasilia, DF, Brazil

e-mail: alan.andrade@embrapa.br

S. Elbelt $\cdot$ P. Marraccini

CIRAD, UMR AGAP, Avenue d'Agropolis, 34398 Montpellier, France

V. A. Silva $\cdot$ F. M. DaMatta

UFV, Departamento de Biologia Vegetal, 36570-000 Viçosa,

MG, Brazil

M. A. G. Ferrão

INCAPER/EMBRAPA CAFÉ, Rua Afonso Sarlo 160,

Bento Ferreira, 29052-010 Vitória, ES, Brazil

Present Address:

V. A. Silva

EPAMIG/URESM, Rodovia Lavras/IJACI, Km 02, CP 176,

37200-000 Lavras, MG, Brazil assimilation $(E T R / A)$ rates that suggested the participation of an alternative electron sink protecting the photosynthetic apparatus against photoinhibition. At the transcriptomic level, high up-regulation of genes encoding for a dehydrin $(\mathrm{CcDH} 3)$, an ascorbate peroxidase (CcAPX1), a prephenate-dehydrogenase like protein $(\mathrm{CCPDHI})$ and a non-symbiotic haemoglobin (CcNSH1) was also observed upon drought suggesting a strong induction of antioxidant and osmoprotection systems in this clone. High expression levels of gene-encoding ABA receptors ( $C C P Y L 3$ and $C C P Y L 7)$ under water limitation were also observed suggesting the involvement of the ABA signaling pathway in response to drought. All these results where compared to those previously obtained for drought-tolerant clones 14 and 120. Our results demonstrated the existence of different mechanisms amongst the drought-tolerant coffee clones regarding water deficit.

Keywords Candidate gene - Coffea canephora - Drought . Gene expression · Real-time quantitative PCR · Water potential
Abbreviations
CG Candidate gene
qPCR Quantitative polymerase chain reaction

\section{Introduction}

In many developing countries, the economy but also the grower's incomes depend on coffee production. In the context of the recognized changes of global climate, coffee growth and yields are expected to be greatly and negatively affected by water limitation (DaMatta and Ramalho 2006; DaMatta et al. 2010). Models already predicted that coffee-growing geographical regions will be affected as a consequence of 
global warming (Assad et al. 2004). The most adverse effects of drought are earlier leaf senescence and shoot die-back that can lead to fruit and flower premature abortion, affecting directly coffee yields and eventually causing plant death in the case of severe stress condition (Waller et al. 2007). Water deficits occurring during the reproduction phase are also known to increase the percentage of bean defects (Silva et al. 2005). We have recently shown that the biochemical composition of beans was also modified by drought occurring during the quiescent phase of coffee development (Vinecky et al. 2010). In such a context, the creation of new varieties better adapted to drought is an important issue.

Genetic variability regarding drought tolerance exists within the Coffea genus, mainly in C. canephora species. Guinean genotypes are considered the most tolerant to drought and genotypes from the SG1 Congolese group are more tolerant to drought than those from the SG2 Congolese group (Montagnon and Leroy 1993). To cope with drought, leaf folding and inclination are the strategies commonly observed for drought-tolerant genotypes. Leaf abscission is then reduced, favouring a rapid recovery of vegetation.

During the last decade, several clones of $C$. canephora presenting drought tolerance and other agronomic traits were characterized (Ferrão et al. 2000) and regrouped into SG1 group of $C$. canephora (Lambot et al. 2008). Differences in root depth, plant-hydraulic conductance and stomatal control of water use, but not osmotic or elastic adjustments, should largely explain the differences in relative tolerance to drought observed between drought-tolerant $\left(\mathrm{D}^{\mathrm{T}}\right)$ and drought-susceptible $\left(\mathrm{D}^{\mathrm{S}}\right)$ clones of $C$. canephora (Pinheiro et al. 2005). This could be related to enhanced activity of antioxidant enzymes in this species like superoxide dismutase (SOD), ascorbate peroxidase (APX), catalase, guaiacol peroxidase, glutathione reductase and dehydroascorbate reductase, for example (Lima et al. 2002; Pinheiro et al. 2004). However no significant differences of activities were observed regarding Reactive Oxygen Species (ROS) detoxifying enzymes between $\mathrm{D}^{\mathrm{T}}$ and $\mathrm{D}^{\mathrm{S}}$ of $C$. canephora (Pinheiro et al. 2005). Regarding sugar metabolism, Praxedes et al. (2006) showed maintenance of sucrose phosphate synthase activity with the decrease of predawn leaf water potential $\left(\Psi_{\mathrm{pd}}\right)$ for the $\mathrm{D}^{\mathrm{T}}$ clone 120 but not for the $\mathrm{D}^{\mathrm{S}}$ clones. According to DaMatta et al. (2003), the better crop yield of $\mathrm{D}^{\mathrm{T}}$ clones compared to $\mathrm{D}^{\mathrm{S}}$ ones, is mainly associated with the maintenance of leaf area and tissue-water potential that are consequences of reduced stomatal conductance $\left(g_{s}\right)$. Such observations suggest the existence of different biological mechanisms conferring drought tolerance in C. canephora.

At the gene expression level, drought also reduced drastically the leaf expression of RBCS1 gene encoding the ribulose-1,5-bisphosphate carboxylase/oxygenase (Rubisco) in plants of $C$. canephora and C. arabica grown in greenhouse and field condition, respectively (Marraccini et al. 2011).
During the same work, significant differences for the rate of decrease in the predawn leaf water potential (RDPWP) were observed between drought-tolerant clones, as the $\Psi$ pd of $-3.0 \mathrm{MPa}$ for the stressed (NI) condition in the greenhouse was reached within 12 days for clones 14 and 120 and 15 days for clone 73. Using the Brazilian Coffee Genome project (Vieira et al. 2006; Mondego et al. 2011) as a source of nucleic database, we recently reported the identification of more than forty candidate genes (CGs) presenting differential expression profiles in leaves of $\mathrm{D}^{\mathrm{T}}$ clones $(14$ and 120$)$ and $\mathrm{D}^{\mathrm{S}}$ clone 22 of C. canephora var. conilon grown in greenhouse with or without water limitation (Marraccini et al. 2012). These CGs were separated in two classes: (i) genes with increased expression under drought, for example like $C c G R P 1, C c H S P 1, C c D H 3$ and $C C A P X 1$ encoding a glycine-rich proteins, heat shock proteins, dehydrins and ascorbate peroxydase, respectively and (ii) genes with decreased expression under drought, like those coding for proteins involved in the photosynthetic reaction (e.g. CcRBCS1, CcCAB1, CcPSBO, CcPSBP and $C C P S B Q$ ), for example.

The present work (i) analyses the characteristics of $\mathrm{D}^{\mathrm{T}}$ clone 73 of C. canephora and (ii) compares the physiological parameters and CG expression profiles in this clone with those previously obtained for the $\mathrm{D}^{\mathrm{T}}$ clones 14 and 120 .

\section{Results}

Physiological Responses of the Drought-Tolerant Clone 73 of C. Canephora

Leaf $\Psi_{\mathrm{pd}}$ close to zero confirmed the unstressed condition of irrigated plants (data not shown). Under irrigation, $\mathrm{D}^{\mathrm{T}}$ clone 73 values of internal to ambient $\mathrm{CO}_{2}$ concentration ratio $\left(C_{i} / C_{a}\right)$, maximum photochemical efficiency $\left(F_{\mathrm{v}} / F_{\mathrm{m}}\right)$, quantum yield of PSII electron transport $\left(\Phi_{\mathrm{PSII}}\right)$, non-photochemical quenching $\left(q_{\mathrm{N}}\right)$, photochemical quenching $\left(q_{\mathrm{P}}\right)$ were equal to those of $\mathrm{D}^{\mathrm{T}}$ clones 14 and 120 (Fig. 1). The same was observed for $P_{\mathrm{E}}$ (fraction of PPF absorbed in PSII antennae and neither used in photochemistry nor dissipated thermally) and electron transport rate/ $\mathrm{CO}_{2}$ assimilation rates $(E T R / A)$. The only differences between these clones concerned the values of $\mathrm{CO}_{2}$ assimilation $(A)$ and stomatal conductance $\left(g_{s}\right)$ which were smaller for the clone 73 than the two others. When established for clone 73 , drought led to decreases in both $g_{\mathrm{s}}$ and $A, 76 \%$ and $90 \%$, compared to $80 \%$ and $73 \%$ for clone 14 and $72 \%$ and $86 \%$ for clone 120 , respectively. For the clone 73 , the $g_{\mathrm{s}}$ reduction was not accompanied by a decrease in the $\mathrm{Ci} / \mathrm{Ca}$ ratios, like observed for clones 14 and 120.

Regarding the maximum photochemical efficiency of PSII (evaluated by the $F_{\mathrm{v}} / F_{\mathrm{m}}$ ratio), similar values were observed under irrigated (I) and non-irrigated (NI) conditions for $\mathrm{D}^{\mathrm{T}}$ clone 73 . These values were also close to that 

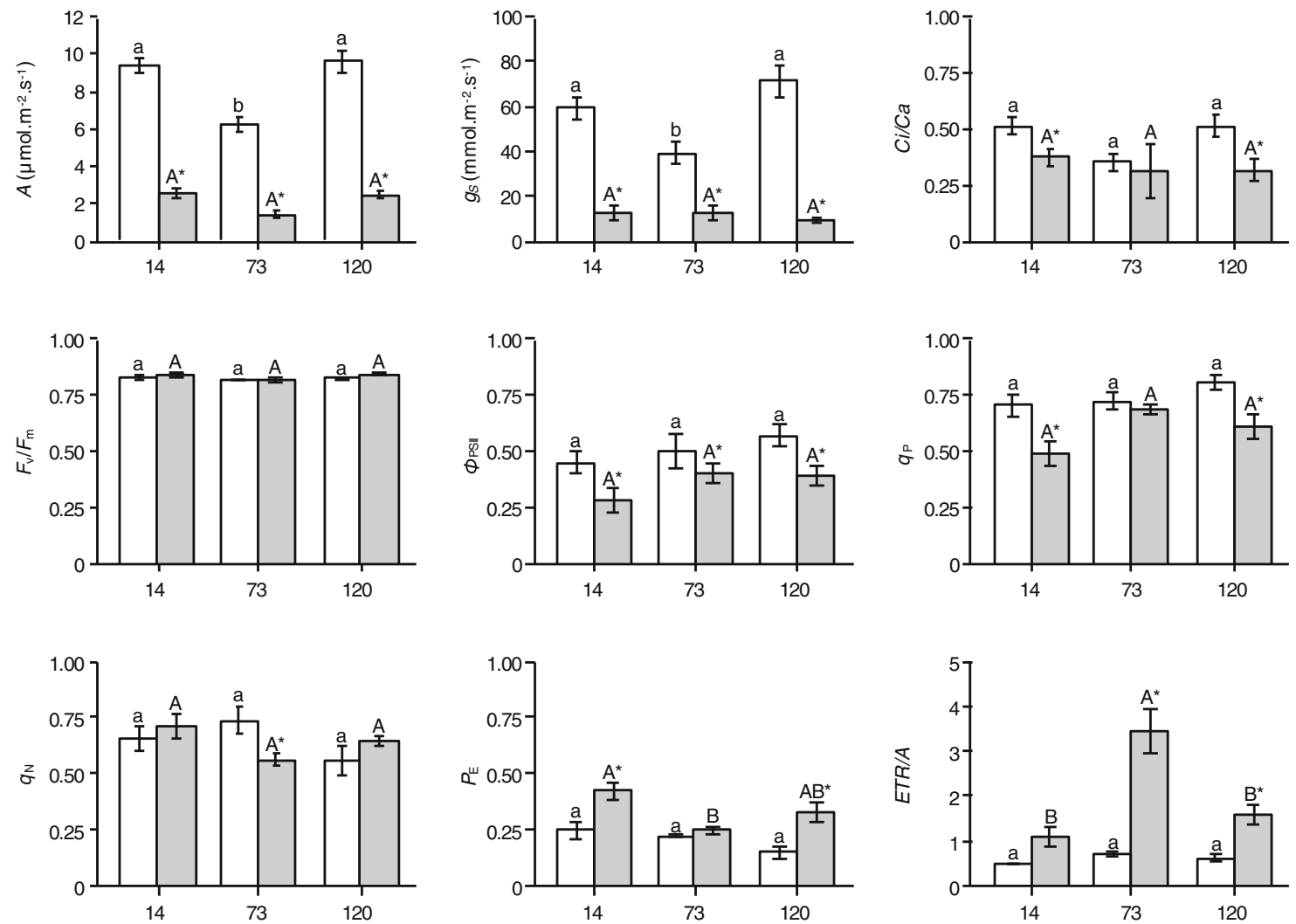

Fig. 1 Effects of drought on physiological parameters. Results of $\mathrm{CO}_{2}$ assimilation rate $(A)$, stomatal conductance $\left(g_{s}\right)$, internal to ambient $\mathrm{CO}_{2}$ concentration ratio $\left(C_{i} / C_{a}\right)$, maximum photochemical efficiency of PSII $\left(F_{\mathrm{v}} / F_{\mathrm{m}}\right)$, quantum yield of PSII electron transport $\left(\Phi_{\mathrm{PSII}}\right)$, photochemical $\left(q_{\mathrm{P}}\right)$ and Stern-Volmer non-photochemical $\left(q_{\mathrm{N}}\right)$ quenching coefficients, the fraction of PPF absorbed in PSII antennae and neither used in photochemistry $\left(P_{\mathrm{E}}\right)$ and electron transport rate/ $\mathrm{CO}_{2}$ assimilation rates $(E T R / A)$ are presented for clones 14, 73 and 120 of $C$.

considered as an optimum ( 0.80$)$, therefore indicating that no photoinhibitory damage occurred. The reduction of $A$ under drought was not accompanied by a reduction of $q_{\mathrm{P}}$ while decreases were observed for $q_{\mathrm{N}}$ and $\Phi_{\mathrm{PSII}}$. It is worth noting that $P_{\mathrm{E}}$ did not increased significantly under NI condition for clone 73 while the contrary was observed for $\mathrm{D}^{\mathrm{T}}$ clones 14 and 120 . In addition, the electron transport $/ \mathrm{CO}_{2}$ assimilation rate $(E T R / A)$ was significantly higher for clone 73 than for the two other clones.

\section{Expression Profiles of Candidate Genes}

The CGs previously identified to present differential expression under drought in leaves of the $\mathrm{D}^{\mathrm{T}}(14$ and 120$)$ and $\mathrm{D}^{\mathrm{S}}$ (22) clones of C. canephora (Marraccini et al. 2012) were tested in $\mathrm{D}^{\mathrm{T}}$ clone 73 . Differential expression relative to drought was analyzed in leaves of this clone by qPCR experiments using the ubiquitin-encoding gene $(C c U B Q 10)$ as endogenous control. These CGs were classified according to their response to drought as shown in the following sections. canephora with (white isobars) or without (grey isobars) irrigation. Different small letters denote significant differences among means of the two genotypes in irrigated conditions. Different capital letters represent significant differences among means of the three genotypes submitted to drought-stress by the Newman-Keuls test at $P \leq 0.05$ (clone effect). Means for drought-stressed plants marked with an asterisk differ from those for control plants by $\mathrm{F}$ test at $P \leq 0.05$ (treatment effect). Each value represents the means $\pm \mathrm{SD}$ of five replicates

\section{Genes with Reduced Expression Under Drought}

Q-PCR experiments showed that the leaf expression of twelve genes in $\mathrm{D}^{\mathrm{T}}$ clones (Fig. 2) was highly reduced under NI condition $(-3.0 \mathrm{MPa})$ when compared to irrigated condition. For example, this was the case for the following genes: $C c C A T 1$ (encoding a catalase isoform 1), CCSDD1 (encoding a subtilisin-like serine protease), CcGAS1 (encoding a glucosyltransferase arbutin synthase, EC 2.4.1.218), CcCCoAOMT1 (encoding a caffeoyl-coenzyme A 3-O methyltransferase) and $C C P P 2 C$ (encoding a type- $2 \mathrm{C}$ protein phosphatase). Expression of genes involved in the photosynthetic process like $C c C A B 1$ (encoding a chlorophyll $\mathrm{a} / \mathrm{b}$ binding proteins), $C C C A 1$ (encoding a carbonic anhydrase), $C C P S B O, C C P S B P$ and $C C P S B Q$ genes coding for OEC proteins of the PSII, was also greatly reduced at $-3.0 \mathrm{MPa}$ (Fig. 2). Like for clone 120, CcAPX2 (encoding an ascorbate peroxidase, isoform 2) gene expression was stable upon drought for clone 73 while it was reduced for clone 14. Interestingly, for CCPYL3 (encoding an abscisic-acid receptor), gene expression clearly decreased for clones 73 and 

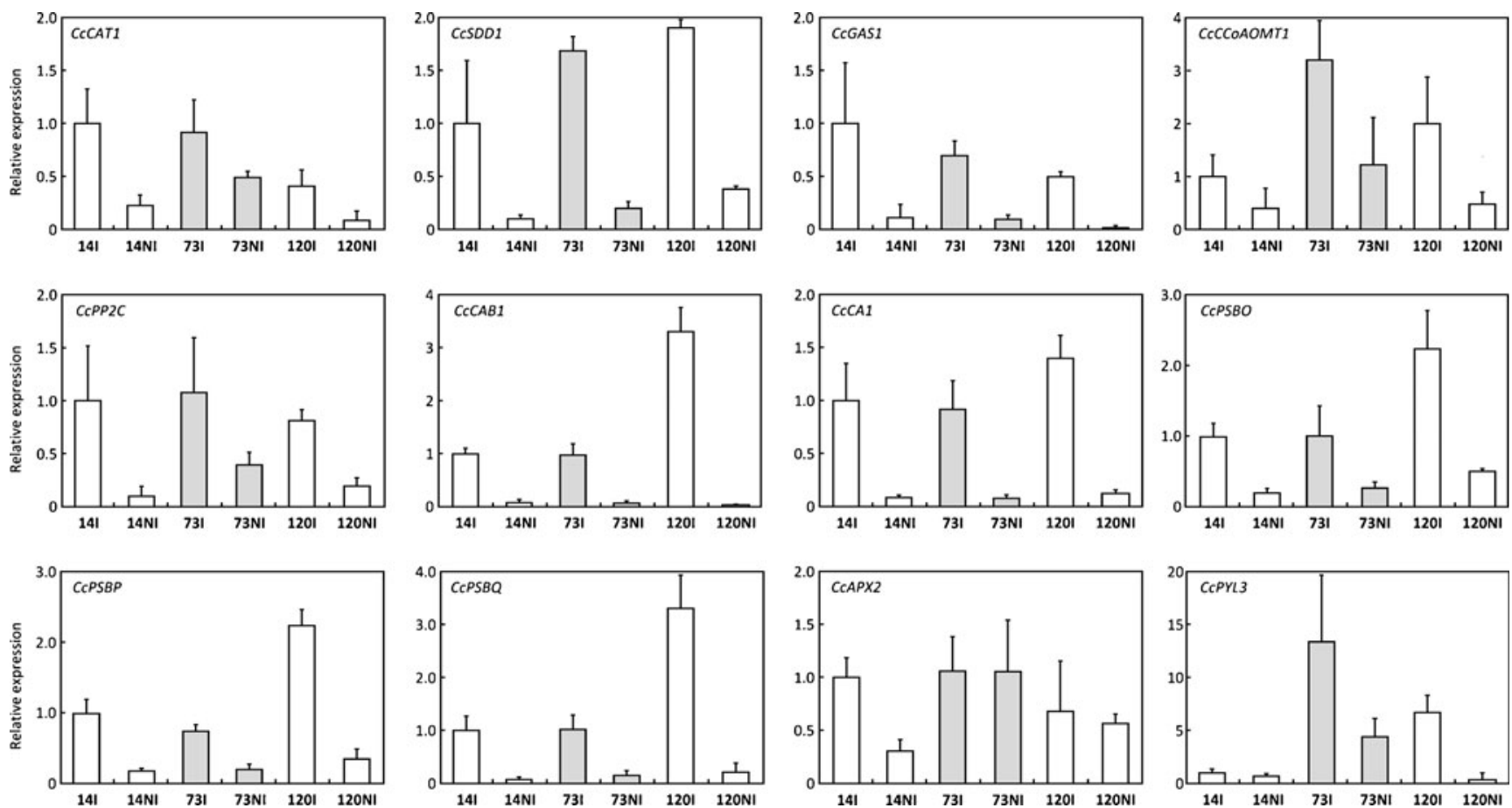

Fig. 2 Expression profiles of genes down-regulated during drought. Gene expression was analysed in leaves of $\mathrm{D}^{\mathrm{T}}$ clone 73 (this work, grey isobar) and compared to those previously obtained for $\mathrm{D}^{\mathrm{T}}$ clones 14 and 120 (white isobars) of C. canephora grown under (I) or without (NI) irrigation (Marraccini et al. 2012). The gene names are indicated in the

120 but not in clone 14 . In that case and whatever the water condition, the CCPYL3 expression was always higher in 73 than in the two other $\mathrm{D}^{\mathrm{T}}$ clones.

\section{Genes with Increased Expression Under Drought}

Q-PCR analyses identified 23 genes with increased expression under drought, as observed for CCMPRI (encoding for the mannose 6-phosphate reductase that converts mannose6-P to mannitol-1-P), $C c G R P 1$ (encoding for a glycine-rich protein), $C c H S P 1$ (encoding a small heat shock protein) and CcUNK10 (encoding for protein of unknown function) for example (Fig. 3). For the latter gene, similar expression profiles were obtained using different endogenous control genes (data not shown). For all $\mathrm{D}^{\mathrm{T}}$ clones, the up-regulation of gene expression observed under water limitation was in the same order of magnitude.

Drought also increased the expression of CCRD29, CcDREB1 and CcRD26 genes, coding for a RD29-like protein, an AP2/ERF DREB-like and a NAC-RD26-like transcription factors, respectively. It is worth noting that the expression of $C c R D 29$ and $C c D R E B 1$ was higher in clone 14 than in clones 73 and 120 under NI condition. For the CcRD26 gene, $\mathrm{D}^{\mathrm{T}}$ clone 73 showed the highest expression. For these three genes, lowest expressions were always observed in clone 120 leaves under water limitation. histograms. Transcript abundances were normalized using the expression of the $C c U B Q 10$ gene as endogenous control. Results are expressed using 14I as reference sample. Values of three technical repetitions are presented as mean $\pm \mathrm{SD}($ bar $)$

Transcript accumulation under drought was also observed for the genes $C c U N K 8$ (unknown function), $C c D H 3$ (encoding a dehydrin), $C C P D H 1$ (encoding a prephenate-dehydrogenase like protein), CCTRAF1 (encoding a TRAF-like [tumor necrosis factor receptor, TNFR] associated factors) and $\mathrm{C} C \mathrm{NSH}$ (encoding a GLB2-like non-symbiotic hemoglobin) genes. For these five genes, gene expression levels observed under $\mathrm{NI}$ condition were always higher in $\mathrm{D}^{\mathrm{T}}$ clone 73 than for the two others.

Drought also up-regulated the expression of CcEDR1 (encoding an enhanced disease resistance [EDR]-like MAPKK kinase protein), $C C H D Z 1$ (encoding a leucine zipper hypothetical protein, isoform 1) and CCAPR1 (encoding an aldosephosphate reductase) genes but in different manners in the three $\mathrm{D}^{\mathrm{T}}$ clones. Up-regulated expression under drought was observed for CCEDR1 gene, the clone 73 showing the highest levels even under unstressed conditions. For CCHDZ1, CCAREB1, CCABI5 and CCAPR1 genes, highest expressions were observed for clone 14 under drought. However, for the two latter regulatory genes, no particular up-regulated expression was noted under drought for clone 73 that displayed unchanged levels.

Different patterns of differential expression were observed between the three $\mathrm{D}^{\mathrm{T}}$ clones for the genes $C C C L P 1$ (encoding a calpain protease [Clp] ATP-binding subunit), CCCAT2 (encoding a catalase isoform 2) and CcUNK1 

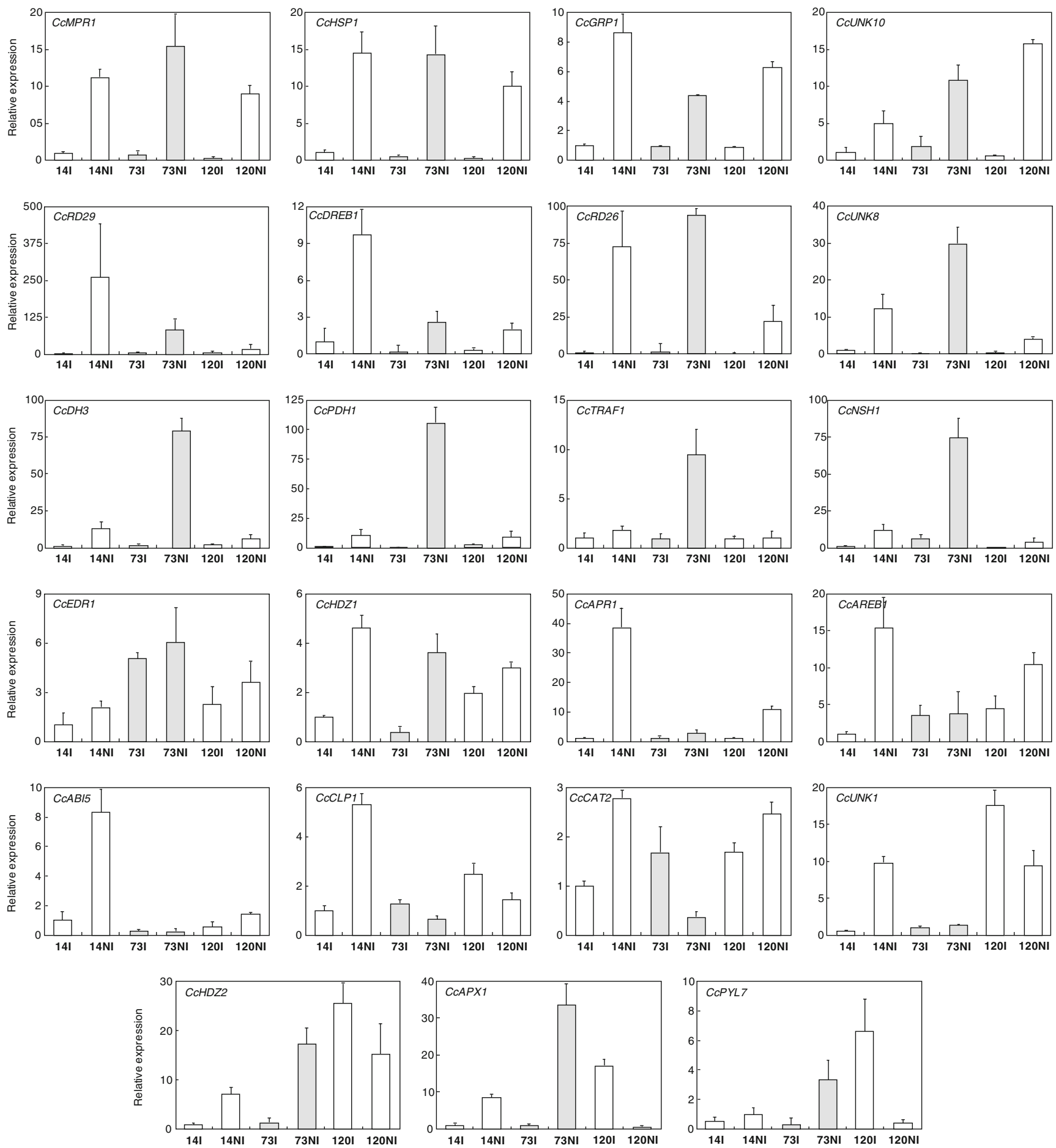

Fig. 3 Expression profiles of genes up-regulated during drought. Gene expression was analysed in leaves of $\mathrm{D}^{\mathrm{T}}$ clone 73 (this work, grey isobar) and compared to those previously obtained for $\mathrm{D}^{\mathrm{T}}$ clones 14 and 120 (white isobars) of C. canephora grown under (I) or without (NI) irrigation (Marraccini et al. 2012). The gene names are indicated in the histograms. Transcript abundances were normalized using the expression of the $C c U B Q 10$ gene as a endogenous control. Results are expressed using 14I as reference sample. Values of three technical repetitions are presented as mean $\pm \mathrm{SD}$ (bar)

regulation was noticed for clone 73. Regarding CcUNK1, gene expression was not affected by water conditions for clone 73 while it decreased for clone 120 and increased for clone 14. Regarding the genes CcHDZ2 (encoding a leucine (unknown). For example, $C c C L P 1$ expression decreased under NI condition in clones 73 and 120 but increased in clone 14. Regarding $C c C A T 2$, up-regulation of expression under drought was observed for clones 14 and 120 while down- 
zipper hypothetical protein, isoform 2), $C c P Y L 7$ (encoding an ABA receptor), and $C C A P X 1$ (encoding an ascorbate peroxidase, isoform 1), expression was clearly induced under NI condition in clone 73 .

\section{Discussion}

The analyses of physiological parameters performed under irrigation revealed lower values of $g_{s}$ and $A$ for $\mathrm{D}^{\mathrm{T}}$ clone 73 than $\mathrm{D}^{\mathrm{T}}$ clones 14 and 120 . This suggested that the former had a greater efficiency in controlling stomatal closure and transpiration and could also explain the slower decline of $\Psi_{\mathrm{pd}}$ of clone $73 \mathrm{com}$ pared to the two others. However, 73 did not show a reduction of $\mathrm{Ci} / \mathrm{Ca}$ under drought, as previously observed for 14 and 120 (Marraccini et al. 2012). The data presented here suggested that the photosynthetic inhibition of $\mathrm{D}^{\mathrm{T}}$ clone 73 was due to stomatal closure or to non-stomatal limitation of photosynthesis, possibly associated with a decrease of Rubisco carboxylation.

For the three $\mathrm{D}^{\mathrm{T}}$ clones, the reduction of $\Phi_{\mathrm{PSII}}$ accompanied with unaltered values of $F_{\mathrm{v}} / F_{\mathrm{m}}$ ratio was probably associated with a PSII inhibition during photosynthesis. Such a reduction should indicate a capacity of photoprotection by adjusting the rate of electron transport to the rate consumption of reducing power under water deficit (Praxedes et al. 2006). In 73, the reduction of $A$ under NI condition was accompanied by a maintenance of $q_{\mathrm{P}}$ and $\mathrm{Ci} / \mathrm{Ca}$ and by a decrease of $q_{\mathrm{N}}$ indicating a participation of an alternative electron sink (Ribeiro et al. 2009). This is confirmed by $E T R / A$ ratio that was significantly higher under drought in clone 73 compared to 14 and 120. This increase of $E T R / A$ ratio represents an imbalance between the electron flow and the $\mathrm{CO}_{2}$ assimilation during photosynthesis, associated with increases in oxygenase activity of Rubisco and might represent an electron flow to other physiological processes rather than to $\mathrm{CO}_{2}$ assimilation reactions (Baker 2008). As a consequence, this photorespiration could protect the photosynthetic apparatus against photoinhibition by limiting electron accumulation and ROS formation. The high expression of CcNHS1 (coding a GLB2-like non-symbiotic haemoglobin) in $\mathrm{D}^{\mathrm{T}}$ clone 73 (see below) also suggest the existence of an active respiration alternative to the mitochondrial electron transport through the use of nitrate (Dordas 2009).

Another difference between $\mathrm{D}^{\mathrm{T}}$ clone 73 with $\mathrm{D}^{\mathrm{T}}$ clones 14 and 120 concerned the fraction of photosynthetic-photon flux absorbed by the PSII antennae and neither used in photochemistry nor dissipated thermally $\left(P_{\mathrm{E}}\right)$. In clone 73 , $P_{\mathrm{E}}$ did not increase under water limitation as observed for clones 14 and 120. In these two clones, this excess of energy can lead to ROS formation by reducing oxygen and protein damages, as suggested by the decrease of photochemical quenching $\left(q_{\mathrm{P}}\right)$. This is not supposed to occur for $\mathrm{D}^{\mathrm{T}}$ clone 73 which showed equal levels of $P_{\mathrm{E}}$ and $q_{\mathrm{P}}$ under irrigated and non-irrigated conditions.
The effects of water suspension on gene expression were analysed in leaves of $\mathrm{D}^{\mathrm{T}}$ clone 73 and compared to those previously obtained in $\mathrm{D}^{\mathrm{T}}$ clones 14 and 120 (Marraccini et al. 2012).

In $\mathrm{D}^{\mathrm{T}}$ clone 73 , gene expression decreased under $\mathrm{NI}$ condition for protein-encoding genes involved in the photosynthesis like $C c C A B 1, C c P S B O, C C P S B P, C C P S B Q$ and $C c C A 1$. These results are similar to those previously observed for the same genes in clones 14 and 120. A similar response was also observed for $C C R B C S 1$ gene expression that decreased with water limitation in $\mathrm{D}^{\mathrm{T}}$ and $\mathrm{D}^{\mathrm{S}}$ clones of $C$. canephora (Marraccini et al. 2011). In agreement with the physiological data, these results can be directly related to a decrease of photosynthesis in leaves of clone 73 (this study), as well as in those of $\mathrm{D}^{\mathrm{T}}$ clones 14 and 120 upon drought (Marraccini et al. 2012). These results can also be associated with the observed inhibition of photosynthesis under water deficit, known to be due to a decrease in $\mathrm{CO}_{2}$ availability caused by the limitation of $\mathrm{CO}_{2}$ diffusion and/or by changes in the biochemical control of photosynthesis in parallel to the inhibition of Rubisco and ATP synthesis (Lawlor 2002). Nevertheless, it is worth noting that under unstressed (irrigated) condition, the expression levels of $C C C A B 1, C C P S B O, C C P S B P$ and $C C P S B Q$ genes were similar for $\mathrm{D}^{\mathrm{T}}$ clones 73 and 14 and lower than those of $\mathrm{D}^{\mathrm{T}}$ clone 120 . The high tolerance to drought of clone 120 photosynthetic apparatus could be directly related to these differences of gene expression (Pinheiro et al. 2004).

The expression of $C C S D D 1$ gene expression coding a negative regulator of guard cell formation (Von Groll et al. 2002) was also investigated. For all clones, a drastic reduction of expression of this gene was observed under drought. In $C$. arabica, Grisi et al. (2008) reported that stomatal density increased upon 10 days of water withdrawal in leaves of the $\mathrm{D}^{\mathrm{T}}$ cultivar Siriema while the contrary was observed in leaves of the $\mathrm{D}^{\mathrm{S}}$ cultivar Catuaí. By analysing different accessions of C. arabica grown under contrasting climatic and biogeographic conditions, higher stomatal frequencies were observed under dry and open (full-sun) condition than under wet-open condition (Kufa and Burkhardt 2011). Stomatal densities at maximal stress were not evaluated for the different $\mathrm{D}^{\mathrm{T}}$ clones of $C$. canephora. However, the putative function of the SDD protein and the decrease of $C c S D D 1$ gene expression under drought seem to be in accordance with increased stomatal densities observed in C. arabica during short- and long-term periods of water withdrawal.

A decrease of $C c C C O A O M T 1$ gene expression upon water limitation was also detected for $\mathrm{D}^{\mathrm{T}}$ clone 73 like previously reported for the $\mathrm{D}^{\mathrm{T}}$ clones 14 and 120 (Marraccini et al. 2012). On the other hand, $C c P D H 1$ gene expression was 10 -fold higher under water limitation in clone 73 than in the two others. Since prephenate-dehydrogenase is involved in the tyrosine synthesis and subsequently phenylalanine which is a precursor of chlorogenic acids (Warpeha et al. 2006), one could suppose that these secondary metabolites 
could participated in the drought-tolerance of clone 73 , (but to a lesser extend in clones 14 and 120), like suggested to occur under cold stress conditions (Fortunato et al. 2010).

A general link between protection against oxidative stress with differences in clonal tolerance to drought was not observed in previous work (Pinheiro et al. 2004). For example, higher catalase (CAT) activities were observed in drought-stressed leaves of $\mathrm{D}^{\mathrm{S}}$ clones 46 and 109A of C. canephora than in $\mathrm{D}^{\mathrm{T}}$ clones 14 and 120. Even if CAT activities were not evaluated for clone 73, our results showed a decrease of $C C C A T 1$ and CCCAT2 gene expression under water limitation. Regarding the ascorbate peroxidase (APX), CCAPXI gene expression increased under water limitation in $\mathrm{D}^{\mathrm{T}}$ clone 73 while $C C A P X 2$ expression was unaltered by water withdrawal. This results are in agreement with higher leaf APX activity detected after water withdrawal in clone 14 than in clone 120 (Pinheiro et al. 2004).

Water withdrawal also increased expression of CCMPRI, $C c G R P 1$ and $C c H S P 1$ genes in $\mathrm{D}^{\mathrm{T}}$ clone 73 . For these genes, clone 73 had similar levels of expression compared to $\mathrm{D}^{\mathrm{T}}$ clones 14 and 120 and to $\mathrm{D}^{\mathrm{S}}$ clone 22 (Marraccini et al. 2012). However, differential expression of M6PR-encoding gene under drought was observed in C. arabica whereby $\mathrm{D}^{\mathrm{T}}$ cultivar IAPAR59 showed a higher increase in expression than $\mathrm{D}^{\mathrm{S}}$ cultivar Rubi (Freire et al. 2013). Regarding the upregulation of CCMPR1, higher mannitol contents might be expected in leaves of drought-stressed coffee where it could serve as a compatible solute or osmoprotectant (Bohnert and Jensen 1996). It is noteworthy that in Arabidopsis transformed with the M6PR gene from celery, this transgene led to the activation of the downstream abscisic acid (ABA) pathway by up-regulation of ABA receptor genes (e.g. PYL4, PYL5, and PYL6) and down-regulation of protein phosphatase 2C genes (ABI1 and ABI2) (Chan et al. 2011), suggesting that mannitol could also act as a signal affecting generesponsiveness to both biotic and abiotic stresses. Our data indicated a decrease of $C c P P 2 C$ gene expression under NI condition in $\mathrm{D}^{\mathrm{T}}$ clone 73 . Silva (2007) showed that severe drought stress $\left(\Psi_{\mathrm{pd}} \approx-3.0 \mathrm{MPa}\right)$ increased $\mathrm{ABA}$ in leaves of $\mathrm{D}^{\mathrm{T}}$ clone 120 of $C$. canephora var. Conilon. Our results also showed differential expression profiles regarding the PIR/ PYL/RCAR type of ABA receptors within the $\mathrm{D}^{\mathrm{T}}$ clones. For example, $C c P Y L 3$ gene expression decreased under NI condition for clones 73 and 120 but was low and relatively unaffected by drought in the case of clone 14. On the other hand, CCPYL7 gene expression increased after water withdrawal in $\mathrm{D}^{\mathrm{T}}$ clone 73 , and to a lower extend in clone 14 , but decreased in clone 120. These results are in accordance with those of Sun et al. (2011) that reported the existence of differential expression patterns of PYL-encoding genes in leaves of tomato subjected to dehydration. Expression profiles of other PIR/PYL/RCAR type-encoding genes should be performed to clarify the differential ABA response among coffee $\mathrm{D}^{\mathrm{T}}$ clones.
Altogether, these results support a probable active ABAsignalling pathway in coffee in response to drought and are in agreement with the function of $\mathrm{PP} 2 \mathrm{C}$ as a negative regulator of this pathway (Hauser et al. 2011). Even if the $C c P P 2 C$ down-regulation under drought would probably sensitize both $\mathrm{D}^{\mathrm{T}}$ and $\mathrm{D}^{\mathrm{S}}$ clones to $\mathrm{ABA}$, the observed differences in gene-expression levels among these clones suggest a more active ABA signalling pathway in $\mathrm{D}^{\mathrm{T}}$ clones 14,73 and 120 than in $\mathrm{D}^{\mathrm{S}}$ clone 22.

The increased expression of the CcGRP1 gene observed in $\mathrm{D}^{\mathrm{T}}$ clone 73 after water suspension is in accordance with the roles played by these proteins in the maintenance, reinforcement and repair during dehydration-rehydration process (Wang et al. 2009). In the same way, a stress-inducible expression of CcHSP1 gene was observed for $\mathrm{D}^{\mathrm{T}}$ clone 73 . For these genes, the expression profiles obtained seem to reflect generic responses of coffee plants to water deficit since similar responses were observed in all $\mathrm{D}^{\mathrm{T}}$ clones.

Water limitation also increased expression of $C c U N K 8$, CcDH3, CcPDH1, CcTRAF1 and CcNSH1 genes in $\mathrm{D}^{\mathrm{T}}$ clone 73. For these genes, expression levels were always higher in 73 than in 14 and 120. These differences can be discussed in relation to the predicted function of corresponding proteins regarding water privation. For example, dehydrins are known to maintain protein folding during desiccation respectively by physical binding to macromolecule (Close 1996). In many plants, ABA was shown to control the expression of dehydrinencoding genes and consequently the accumulation of corresponding proteins under dehydration (Wang et al. 2002). In that sense, a high amount of dehydrin expected to occur in clone 73 as a consequence to the great increase of $\mathrm{CcDH} 3$ expression under drought could participate in the drought tolerance of this clone by maintaining water status (Santos and Mazzafera 2012).

Regarding $\mathrm{CcNSH1}$, encoding a non-symbiotic hemoglobin (nsHb), expression was 12-fold higher under irrigation condition and 6- and 20-fold higher under non irrigation condition in clone 73 than in 14 and 120, respectively. Non-symbiotic haemoglobins have been shown to be involved in a sequence of events termed as the nsHb/NO (nitric oxide) cycle in which $\mathrm{NO}$ reacts with ns- $\mathrm{HbO}_{2}$ and produces nitrate $\left(\mathrm{NO}_{3}^{-}\right)$(Dordas 2009). By scavenging NO molecules, the reactions involved in this cycle oxidize $\mathrm{NAD}(\mathrm{P}) \mathrm{H}$, therefore maintaining redox status and glycolysis of the cell. Recent data also showed that the induction of antioxidant defences by drought and ABA required the production of NO (Zhang et al. 2007), indicating that this molecule function as an important endogenous plant signalling able to mediate several developmental and physiological processes (Neill et al. 2008). Thus, the lower scavenging capacity of $\mathrm{CcNSH} 1$ protein expected to occur for $\mathrm{D}^{\mathrm{T}}$ clones 14 and 120, suggests that NO levels might be higher in these clones than in clone 73. Due to oxidative burst caused by drought and the protective role played by 
HSPs, dehydrins and nsHbs, the increase of their corresponding gene expression reported here is in accordance with responses usually observed in other plant species under water limitation (Shinozaki and Yamaguchi-Shinozaki 1997).

In plants, it is well known that two pathways of signal transduction exist in the control of stress-related genes: one dependent of ABA and another independent of this phytohormone (Yamaguchi-Shinozaki and Shinozaki 2005). In this scheme, it was demonstrated that transcription factors belonging to the ERF/AP2 family (e.g. DREB), but also NAC/HD-ZIP transcription factors, controlled co-operatively or separately the RD29A gene expression in an ABAindependent manner. On the other hand, the expression of MYB/MYC transcription factors that controls, for example the expression of the genes $R D 20 \mathrm{~A}, 22$ and $29 \mathrm{~B}$, was shown to be ABA-dependent. The results presented here for $\mathrm{D}^{\mathrm{T}}$ clone 73 also demonstrated that water deficit increased the expression of regulatory genes $C c D R E B 1, C c R D 26, C c R D 29$, $C c H D Z 1$ and $C c H D Z 2$ but also of $C c E D R 1$. For these genes, expression levels of CcRD26 and CcEDR1 were higher in clone 73 than in clones 14 and 120 . The clone 73 also displayed mRNA levels of $C C A B I 5$ and $C C A R E B 1$ unaffected by drought and lower than those of $\mathrm{D}^{\mathrm{T}}$ clones 14 and 120 . These two genes comprise components of the ABAdependent pathway while $C c H D Z 1, C c H D Z 2, C c D R E B 1$ and $C c R D 26$ are implicated in the ABA-independent signals (Yamaguchi-Shinozaki and Shinozaki 2005). As described before for the PIR/PYL/RCAR type-encoding genes, the differential expression observed among $\mathrm{D}^{\mathrm{T}}$ clones also suggests that they respond in a different manner to drought. Altogether, results presented here clearly demonstrate that different mechanisms account for drought tolerance in coffee plants as recently demonstrated by morphological and physiological analyses (Silva et al. 2013). Our results also suggest that the molecular responses to drought in coffee plants involve components of both ABA-dependent and ABA-independent pathways. Ongoing RNAseq experiments from roots of $\mathrm{D}^{\mathrm{T}}$ clones grown under different water regimes will further increment our understanding on this important agronomic trait.

\section{Methods}

\section{Plant Material}

The $\mathrm{D}^{\mathrm{T}}$ clone 73 of $C$. canephora Pierre was obtained as rooted stem cuttings from the Institute for Research and Rural Assistance (Incaper, Vitoria, Espírito Santo, Brazil) (Ferrão et al. 2000) and grown in greenhouse (Federal University of Viçosa-UFV, Minas Gerais, Brazil) condition $\left(25{ }^{\circ} \mathrm{C}, 70 \% \mathrm{RH}\right.$, average midday photosynthetic photon flux of $900 \mu \mathrm{mol} \mathrm{m}^{-2} \mathrm{~s}^{-1}$ ) in pots of $12 \mathrm{~L}$ of a mixture of soil, sand and manure $(3: 1: 1, \mathrm{v} / \mathrm{v} / \mathrm{v})$ at the same experimental setting as for clones 14, 22 and 120, previously analyzed (Marraccini et al. 2011, 2012). After 6 months, plants were separated in two groups: the first one received regular irrigation (I: control) while irrigation was suspended for the second (NI: drought stress). For both conditions, six plants (biological repetitions) were analyzed. Fresh leaves (fully expanded leaves corresponding to the $3 \mathrm{rd}$ pair in plagiotropic branches) were used for physiological and molecular analyses.

Leaves were collected at daytime (around 10:00 am), immediately frozen in liquid nitrogen and further stored in the temperature of $-80{ }^{\circ} \mathrm{C}$ for RNA extractions.

\section{Physiological Analyses}

Drought acclimation was evaluated by measuring leaf predawn water potential $\left(\Psi_{\mathrm{pd}}\right)$ with a Scholander-type pressure chamber. $\Psi_{\mathrm{pd}}$ was regularly followed to reach near -3.0 MPa for drought-stressed plants (Silva et al. 2010). This was accomplished in 12 days for $D^{T}$ clones 14 and 120 and 15 days for $\mathrm{D}^{\mathrm{T}}$ clone 73 (Marraccini et al. 2011). Net $\mathrm{CO}_{2}$ assimilation rate $(A)$, stomatal conductance to water vapour $\left(g_{s}\right)$ and internal to ambient $\mathrm{CO}_{2}$ concentration ratio $\left(C_{i} / C_{a}\right)$ were measured between 10:00 $\mathrm{h}$ and noon under artificial and saturating PPF (photosynthetic photon flux) with a portable open-system infrared gas analyzer (LCpro+, Analytical Development Co. Ltd, Hoddesdon, UK) under a relative humidity of around $80 \%$. The chlorophyll $a$ fluorescence parameters were measured using a portable pulse amplitude modulation fluorometer (FMS2, Hansatech, King's Lynn, Norfolk, UK). The maximum photochemical efficiency of PSII $\left(F_{\mathrm{v}} / F_{\mathrm{m}}\right)$, the coefficient of photochemical quenching $\left(q_{\mathrm{P}}\right)$, the quantum yield of photosystem II electron transport $\left(\Phi_{\mathrm{PSII}}\right)$, the nonphotochemical quenching (NPQ) and the fraction of PPF absorbed in PSII antennae and neither used in photochemistry $\left(P_{\mathrm{E}}\right)$ were measured as previously described (Lima et al. 2002; Pinheiro et al. 2004). For each parameter, values represent the mean \pm SD of five replicates.

\section{RNA Extraction}

Samples were ground into a powder in liquid nitrogen and total RNAs were extracted as described previously (Marraccini et al. 2011). RNA quantification was performed using a NanoDrop ${ }^{\mathrm{TM}} 1000$ Spectrophotometer (Waltham, MA, USA).

\section{Real-Time RT-PCR Assays}

Samples were treated with RQ1 RNase-free DNase according to the manufacturer's instructions (Promega, Madison, WI, USA) to eliminate contaminant genomic DNA. Synthesis of first strand cDNA was done by treating $1 \mu \mathrm{g}$ 
of total RNA with the ImProm-II ${ }^{\mathrm{TM}}$ Reverse Transcription System with oligo $\left(\mathrm{dT}_{15}\right)$ according to the manufacturer's recommendations (Promega). Real-time RT-PCR assays were carried out using the 7500 Fast Real-Time PCR Systems (Applied Biosystems, Foster City, CA, USA) as described previously (Marraccini et al. 2011). cDNA preparations were diluted $(1 / 25$ to $1 / 100)$ and tested by qPCR using CG-primer pairs previously reported (Marraccini et al. 2012) that were preliminary tested for their specificity and efficiency against a mix of cDNA (data not shown). The qPCR was performed with SYBR green fluorochrom (SYBRGreen qPCR Mix-UDG/ROX, Invitrogen) according to the supplier recommendation. Data were analyzed with the SDS 2.1 software (Applied Biosystems) and normalized using the expression of $C c U B Q 10$ endogenous control (Barsalobres-Cavallari et al. 2009). Expression levels were calculated by applying the formula $(1+\mathrm{E})^{-\Delta \Delta \mathrm{Ct}}$ where $\Delta \mathrm{Ct}$ target $=\mathrm{Ct}$ target gene $-\mathrm{Ct}{ }_{C c U B Q 10}$ and $\Delta \Delta \mathrm{Ct}=\Delta \mathrm{Ct}$ target $-\Delta \mathrm{Ct}$ reference sample, the 14I always being the reference sample (expression level equal to 1 ).

\section{Statistical Analyses}

The experiment was a completely randomized block design, with six treatment combinations, forming a $3 / 2$ factorial (three clones and two watering regimes) with five blocks. The experimental plot was one plant per container. All of the statistical analyses were performed using the Sisvar system (Ferreira 2011). Significant differences between treatment means were tested by the Newman-Keuls(clone effect) and F-tests (treatment effect), at $P<0.05$.

Acknowledgments This work was carried out under the project of scientific cooperation Embrapa-Cirad "Genetic determinism of drought tolerance in coffee". The authors acknowledge the financial support from the Brazilian Coffee R\&D Consortium, FINEP and INCT-café (CNPq/FAPEMIG). The authors would like to thank Drs Aymbiré Francisco Almeida da Fonseca and Romário Gava Ferrão from the INCAPER Institute for providing plant materials and are also grateful to Dr. T. Leroy for discussions and critical reading of the manuscript.

\section{References}

Assad ED, Pinto HS, Zullo J Jr, Ávila AMH (2004) Impacto das mudanças climáticas no zoneamento agroclimático do café no Brasil. Pesqui Agrop Bras 39:1057-1064

Baker NR (2008) Chlorophyll fluorescence: a probe of photosynthesis in vivo. Annu Rev Plant Biol 59:89-113

Barsalobres-Cavallari CF, Severino FE, Maluf MP, Maia IG (2009) Identification of suitable internal control genes for expression studies in Coffea arabica under different experimental conditions. BMC Mol Biol 10:1

Bohnert HJ, Jensen RG (1996) Strategies for engineering water stress tolerance in plants. Trends Biotechnol 14:89-97

Chan Z, Grumet R, Loescher W (2011) Global gene expression analysis of transgenic, mannitol-producing, and salt-tolerant Arabidopsis thaliana indicates widespread changes in abiotic and biotic stressrelated genes. J Exp Bot 62:4787-4803

Close TJ (1996) Dehydrins: emergence of a biochemical role of a family of plant dehydration proteins. Physiol Plant 97:795-803

DaMatta FM, Ramalho JC (2006) Impact of drought and temperature stress on coffee physiology and production: a review. Braz J Plant Physiol 18:55-81

DaMatta FM, Chaves ARM, Pinheiro HA, Ducatti C, Loureiro ME (2003) Drought tolerance of two field-grown clones of Coffea canephora. Plant Sci 164:111-117

DaMatta FM, Grandis A, Arenque BC, Buckeridge MS (2010) Impacts of climate changes on crop physiology and food quality. Food Res Int 43:1814-1823

Dordas C (2009) Non symbiotic hemoglobins and stress tolerance in plants. Plant Sci 176:433-440

Ferrão RG, Fonseca AFA, Silveira JSM, Ferrão MAG, Bragança SM (2000) EMCAPA 8141 - Robustão Capixaba, variedade clonal de café conilon tolerante à seca, desenvolvida para o estado do Espírito Santo. Rev Ceres 47:555-559

Ferreira DF (2011) Sisvar: a computer statistical analysis system. Ciência Agrotech 35:1039-1042

Fortunato A, Lidon FC, Batista-Santos P, Leitão AE, Pais IP, Ribeiro AI, Ramalho JC (2010) Biochemical and molecular characterization of the antioxidative system of Coffea sp. under cold conditions in genotypes with contrasting tolerance. J Plant Physiol 167:333-342

Freire LP, Marraccini P, Rodrigues GC, Andrade AC (2013) Análise da expressão do gene da manose 6 fosfato redutase em cafeeiros submetidos ao déficit hídrico no campo. Coffee Sci 8:17-23

Grisi FA, Alves JD, de Castro EM, de Oliveira C, Biagiotti G, de Melo LA (2008) Avaliações anatômicas foliares em mudas de café 'Catuaí' e 'Siriema' submetidas ao estresse hídrico. Ciênc Agrotech 32:1730-1736

Hauser F, Waadt R, Schroeder JI (2011) Evolution of abscisic acid synthesis and signaling mechanisms. Curr Biol 21:346-355

Kufa T, Burkhardt J (2011) Stomatal characteristics in Arabica coffee germplasm accessions under contrasting environments at Jimma, southwestern Ethiopia. Int J Bot 7:63-72

Lambot C, Crouzillat D, Aymbire FAF, Leloup V, Broun P, Pétiard V (2008) Evaluation of conilons for genetic diversity, cup quality and biochemical composition. In: Association for Science and Information on Coffee ASIC (ed) Proceedings of the 22nd International Conference on Coffee Science, Campinas, 2008

Lawlor DW (2002) Limitation to photosynthesis in water-stressed leaves: stomata vs. metabolism and the role of ATP. Ann Bot 89:871-885

Lima ALS, DaMatta FM, Pinheiro HA, Totola MR, Loureiro ME (2002) Photochemical responses and oxidative stress in two clones of Coffea canephora under water stress. Environ Exp Bot 47:239-247

Marraccini P, Freire LP, Alves GSC, Vieira NG, Vinecky F, Elbet S, Ramos HJO, Rodrigues GC, Montagnon C, Vieira LGE, Silva VA, Leroy T, Pot D, Andrade AC (2011) RBCS1 expression in coffee: Coffea orthologs, Coffea arabica homeologs, and expression variability between genotypes and under drought stress. BMC Plant Biol 11:85

Marraccini P, Vinecky F, Alves GSC, Ramos HJO, Elbelt S, Vieira NG, Carneiro FA, Sujii PS, Alekcevetch JC, Silva VA, DaMatta FM, Ferrão MAG, Leroy T, Pot D, Vieira LGE, da Silva FR, Andrade AC (2012) Differentially expressed genes and proteins upon drought acclimation in tolerant and sensitive genotypes of Coffea canephora. J Exp Bot 63:4191-4212

Mondego JMC, Vidal RO, Carazzolle MF, Tokuda EK, Parizzi LP, Costa GGL, Pereira LFP, Andrade AC, Colombo CA, Vieira LGE, Pereira GAG, for Brazilian Coffee Genome Project Consortium (2011) An EST-based analysis identifies new genes and reveals distinctive gene expression features of Coffea arabica and Coffea canephora. BMC Plant Biol 11:30 
Montagnon C, Leroy T (1993) Réaction à la sécheresse de jeunes caféiers Coffea canephora de Côte-d'Ivoire appartenant à différents groupes génétiques. Café Cacao Thé 37:179-190

Neill S, Barros R, Bright J, Desikan R, Hancock J, Harrison J, Morris P, Ribeiro D, Wilson I (2008) Nitric oxide, stomatal closure, and abiotic stress. J Exp Bot 59:165-176

Pinheiro HA, DaMatta FM, Chaves ARM, Fontes EPB, Loureiro ME (2004) Drought tolerance in relation to protection against oxidative stress in clones of Coffea canephora subjected to long-term drought. Plant Sci 167:1307-1314

Pinheiro HA, DaMatta FM, Chaves ARM, Loureiro ME, Ducatti C (2005) Drought tolerance is associated with rooting depth and stomatal control of water use in clones of Coffea canephora. Ann Bot 96:101-108

Praxedes SC, DaMatta FM, Loureiro ME, Ferrão MAG, Cordeiro AT (2006) Effects of long-term soil drought on photosynthesis and carbohydrate metabolism in mature robusta coffee (Coffea canephora Pierre var. kouillou) leaves. Environ Exp Bot 56:263-273

Ribeiro RV, Machado EC, Santos MG, Oliveira RF (2009) Photosynthesis and water relations of well-watered orange plants as affected by winter and summer conditions. Photosynthetica 47:215-222

Santos AB, Mazzafera P (2012) Dehydrins are highly expressed in water-stressed plants of two coffee species. Trop Plant Biol 5:218-232

Shinozaki K, Yamaguchi-Shinozaki K (1997) Gene expression and signal transduction in water-stress response. Plant Physiol 115:327-334

Silva VA (2007) Caracterização fisiológica da tolerância à seca em Coffea canephora: contribuição relativa do sistema radicular e da parte aérea. Dissertation, Federal University of Viçosa (UFV)

Silva EA, Mazzafera P, Brunini O, Sakai E, Arruda FB, Mattoso LHC, Carvalho CRL, Pires RCM (2005) The influence of water management and environmental conditions on the chemical composition and beverage quality of coffee beans. Braz J Plant Physiol 17:229-238

Silva VA, Antunes WC, Guimarães BLS, Paiva RMC, Silva VF, Ferrão MAG, DaMatta FM, Loureiro ME (2010) Physiological response of Conilon coffee clone sensitive to drought grafted onto tolerant rootstock. Pesqui Agrop Bras 45:457-464

Silva PEM, Cavatte PC, Morais LE, Medina EF, DaMatta FM (2013) The functional divergence of biomass partitioning, carbon gain and water use in Coffea canephora in response to the water supply: implications for breeding aimed at improving drought tolerance. Environ Exp Bot 87:49-57

Sun L, Wang YP, Chen P, Ren J, Ji K, Li Q, Li P, Dai SJ, Leng P (2011) Transcriptional regulation of SIPYL, SIPP2C, and SlSnRK2 gene families encoding ABA signal core components during tomato fruit development and drought stress. J Exp Bot 62:5659-5669

Vieira LGE et al (2006) Brazilian coffee genome project: an EST-based genomic resource. Braz J Plant Physiol 18:95-108

Vinecky F, Davrieux F, Alves GSC, Mera AC, Leroy T, Bonnot F, Pot D, Rocha OC, Guerra AF, Rodrigues GC, Marraccini P, Andrade AC (2010) Effects of water stress on bean biochemical composition of Coffea arabica cv. Rubi. In: Association for Science and Information on Coffee ASIC (ed) Proceedings of the 23rd International Conference on Coffee Science, Bali, 2010

Von Groll U, Berger D, Altmann T (2002) The subtilisin-like serine protease SDD1 mediates cell-to-cell signaling during Arabidopsis stomatal development. Plant Cell 14:1527-1539

Waller JM, Bigger M, Hillocks RJ (2007) Coffee pests, diseases and their management. CABI Pub, Wallingford

Wang XJ, Loh CS, Yeoh HH, Sun WQ (2002) Drying rate and dehydrin synthesis associated with abscisic acid-induced dehydration tolerance in Spathoglottis plicata orchidaceae protocorms. J Exp Bot 53:551-558

Wang L, Shang H, Liu Y, Zheng M, Wu R, Phillips J, Bartels D, Deng X (2009) A role for a cell wall localized glycine-rich protein in dehydration and rehydration of the resurrection plant Boea hygrometrica. Plant Biol 11:837-848

Warpeha KM, Lateef SS, Lapik Y, Anderson M, Lee B-S, Kaufman LS (2006) G-protein-coupled receptor 1, G-protein G $\alpha$-subunit 1, and prephenate dehydratase 1 are required for blue light-induced production of phenylalanine in etiolated Arabidopsis. Plant Physiol 140:844-855

Yamaguchi-Shinozaki K, Shinozaki K (2005) Organization of cis-acting regulatory elements in osmotic- and cold-stress-responsive promoters. Trends Plant Sci 10:88-94

Zhang A, Jiang M, Zhang J, Ding H, Xu S, Hu X, Tan M (2007) Nitric oxide induced by hydrogen peroxide mediates abscisic acidinduced activation of the mitogen-activated protein kinase cascade involved in antioxidant defense in maize leaves. New Phytol $175: 36-50$ 